\title{
BIM-Based Simulator for Rebar Placement
}

\author{
Park, U-Yeol* \\ Department of Architecture Engineering, Andong National University, Andong-Si, Kyoungsangbuk-Do, 760-749, \\ Korea
}

\section{Abstract}

Reinforcing bars (rebar) comprise an integral part of a concrete structure, and play a major role in the safety and durability of the building. However, the actual placement or installation of rebar is not planned and controlled by the detailer. Recently, 4D simulations, using 3D model and scheduling software, have been used to improve the efficiency of the construction phrase. However, 4D simulators have not been introduced at the detailed level of work, such as rebar placement. Therefore, this paper suggests a BIM-based simulator for rebar placement to determine the sequence with which rebar is placed into the form. The system using Autodesk Revit API automatically generates rebar placement plans for a building structure, and labels the placement sequence of each individual bar or set of bars with ascending numbers. The placement sequence is then visualized using Autodesk Revit Structure 2012. This paper provides a short description of a field assessment and limits.

Keywords : reinforcement bar, BIM(Building Information Modeling), clash detection, four-dimensional, simulation

\section{Introduction}

\subsection{Background and objective}

The placement of reinforcing bars (rebars) has a great impact on the cost and quality of a structure. The rebars should be placed on the proper places in accordance with the drawings and specification to provide structural performance. To secure durability, the minimum concrete cover should be maintained. In addition, although rebars occupies a small portion of the volume of reinforced concrete, their contribution to the cost is approximately equal to that of concrete [1]. Therefore, to reduce the construction cost, the

\section{Received : October 13, 2011}

Revision received : November 28, 2011

Accepted : December 15, 2011

* Corresponding author :Park, U-Yeol

[Tel: 82-54-820-5897, E-mail: wypark@andong.ac.kr]

(c)2012 The Korea Institute of Building Construction, All rights reserved. rebar work should be improved, so some of research was done to improve the quality and reduce the cost by performing an analysis of the actual condition of rebar work [2, 3].

To perform the rebar work, after winning a contract, a subcontractor specialized in the rebar work prepares a rebar placing drawings itself or places an order to prepare it to a detailer, and then bar lists are prepared by collecting the data on the rebars by shape and size. Based on the bar lists, rebars are fabricated in a construction jobsite or a fabricating shop. After bar fabrication, rebars were delivered and placed by Ironworkers [4]. Due not only to the low utilization of placing drawings in the past but also to the manual creation of the placing drawings and the rebar lists [5], some studies have been carried out on the development of a CAD-based system that can create such documents automatically [6,7]. As the rebar information is usually created first at the 
structural design stage, the idea of an integrated automation process, from extracting the rebar information from the structural designs to generating the placing drawings and the rebar lists and calculating the rebar quantities to be used [8], was presented at the early stage. Ideally, the entire process would be integrated like this, but it is actually impossible to achieve this in reality, as frequent changes in design take place. Therefore, based on the structural drawings delivered to the constructor, it is realistic to simply automate the process after which structural drawings is delivered over a general contractor.

The rebar work consists of preparation of the placing drawings, a job superintendent' $\mathrm{s}$ approval of placing drawings, and placement of the rebars at the job site. When the placing drawings and the bar lists are prepared, the placement sequence is not usually taken into account. If the placement sequence is not considered, a considerable amount of time is wasted for searching, identifying, rehandling, etc., of rebar [1]. Inappropriate placement of a rebar can lead to falling behind the schedule because of reprocessing. For this reason, when the placement sequence is considered, the productivity of rebar work will be improved, and therefore the need for development of a simulator that can review the placement sequence is pressing.

BIM (Building Information Modeling) is actively studied as a means of finding a problem and preparing measures for it through a review in advance of an actual work. 4D CAD simulation is used in the field as part of improving efficiency of the work between processes including clash detection at the construction stage. In addition research on auto link between the process and objects [9] is in progress.

Clashes are checked on construction-structure, structure-MEP, and construction-MEP to correct any errors in the drawings [10]. Clashes between physical objects can be easily found, but it is hard to perform a clash detection on structures such as struts in the underground construction or an underground structure that is dismantled or constructed according to the schedule, because the clashes might not take place according to construction sequence. Thus, if the clash detection is done according to the schedule, cashes can be checked easily and any error in the construction stage can be found and corrected [11].

A construction simulation enables a review to be performed in advance of the actual work, reveals the problems in the construction work to review the drawings, and corrects the errors that have been found, and many studies have been done in this area. Based on the 3D object model, an object library was built to conduct the integrated management of design and construction information, and a prototype 4D simulation was presented, in which the object library was integrated with the information of processing and construction plans [12]. Diverse studies to improve the usability of $4 \mathrm{D}$ simulation have been carried out $[13,14,15]$, and multiple commercial software packages have been developed and utilized in the business practice. As noted in the previous research [5], the software is excellent in the visual aspect, but too much stress has been placed on the visual function at the expense of providing a function to manage other processes or construction plans. In addition, the conventional software can run a simulation with the concrete member unit, but does not provide any function to simulate a detailed unit such as a rebar unit.

BIM can be utilized in many ways using the geometric information and other properties of 3D objects. It is believed that if a simulation is performed not only of the process of an entire 
project but also of work sections in detail, BIM can be applied to various fields of construction management. According to the structural code and specifications, rebars should be placed appropriately, so a thorough plan is needed for smooth progress. Therefore, if the placing sequences can be reviewed using an appropriate simulation tool, both the quality of the rebar work and overall constructability can be improved.

Therefore, this research aims to develop a simulator that can review the placement sequence based on BIM. By using the simulator, the problems in placement can be reviewed beforehand, and the quality of rebar work will be improved and the constructability will also be advanced accordingly.

\subsection{Scope definition and method}

Several interest parties participate in the rebar work including a general contractor, a rebar placing subcontractor, a detailer and a fabricating shop. With the timeline of rebar work schedule, the placing drawings and the rebar lists are created based on the structural drawings and specifications and delivered. Since some information can be missed or an error might occur, it is ideal to develop an integrated management system of all the information of rebar work from start to end. From this perspective, many studies have been conducted to draw up rebar lists from the placing drawings and the rebar lists $[6,7,8]$. However, there are few studies reported on consideration of the placement sequence when the placing drawings are prepared and on auto-creation of the rebar lists. Thus, this research is to improve constructability focusing on the post-stage of the preparation of the placing drawings and develop a simulator that can automatically create the placement sequence.
A reinforced concrete structure consists of members including base, columns, walls and slabs. Considering the complexity of rebar placement, few types of rebar are used in vertical members such as base and columns and walls, and the placement sequence is not complex. On the other hand, many different types of rebar are used in the horizontal members including beams or slabs, and highly complicated regulations should be followed to perform the work. For this reason, the research scope is restricted to review the constructability for the horizontal members like beams and slabs except for columns and walls and create the placement sequence.

As the research process, literature on CAD-based automation of rebar placement and BIMrelated research recently used in the construction industry were reviewed to set the research direction. Then, a plan and algorithm was presented to use BIM data in a rebar placement simulation. Although there are several tools that can run a rebar placement simulator, AutoCADR Revit $\mathbb{R}$ Structure 2012 most widely used in Korea was used.

\section{Development of a rebar placement simulator}

The system consists of the clash detection function and the simulator to perform a simulation of the placement process according to the placement sequence. This system is implemented using Revit API (Application Programming Interface) of Autodesk. Revit API provides a function to create and edit a Revit model using an external programming language. In this research, Visual C\# 2010 Express was used.

\subsection{Clash detection}

When the placing drawings are made, the clash detection is not usually performed [1]. For this 
reason, there are cases in which the appropriate distance is not secured, or the load bearing capacity of the structure is weakened due to clashes. Thus, by checking the clashes between rebars in advance, constructability and structural performance should be improved.

BIM-based clash detection between members is now being utilized $[9,10,11]$. To check the clashes of rebar, geometric details and information on other properties is needed. The coordinate information of the center line of rebar extracted by Revit Structure 2012 was utilized to determine whether interference took place. When the distance between center lines was smaller than the diameter of the rebar, it was considered that a clash took place.

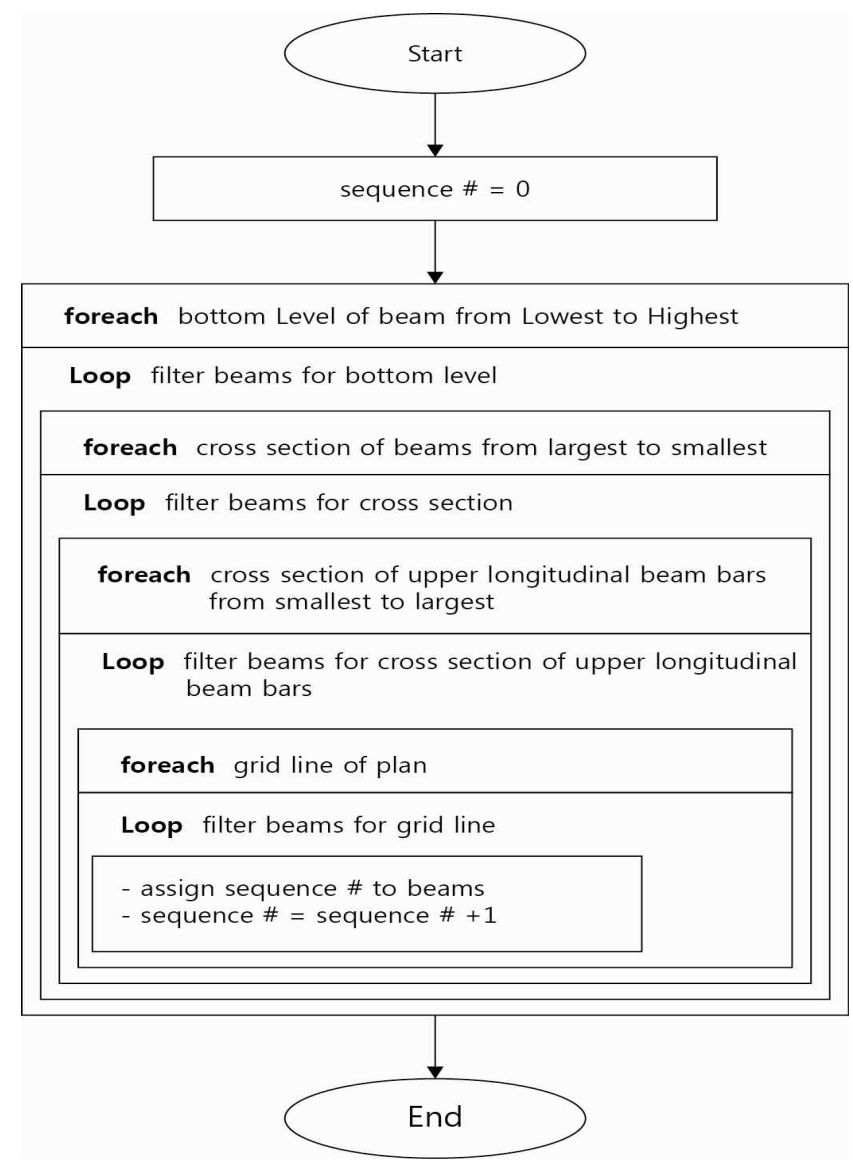

Figure 1. The procedure for sequencing individual beams

\subsection{A simulator for rebar placement}

In general, rebars are placed in vertical members like columns and walls and then in horizontal members like beams and slabs. There is little restriction for determining the placement sequence in the vertical members such as columns and walls, but structural stability and constructability should be taken into account when placing rebars in beams and slabs.

Since no crosssections of beams done on the same story are the same, it is almost impossible to determine a standard placement sequence that satisfies all the conditions. The rebar is usually placed first in beams with a larger cross-section or that serve a structurally important role, as these generally have many rebars placed within them. In addition, to the greatest extent possible, a sequence should be followed which will not necessitate, as much as possible, the necessity of threading bars in and around previously placed bars at intersections [16]. Therefore, as indicated in Figure 1, an algorithm to determine the placement sequence of beams was implemented in this research. It is considered that the greater the beam height, the more load the beam bears, and for this reason it is desirable to work the beam with the lowest height first to reduce such threading bars afterward. In addition, all of the beams on a grid are generally placed at once, and the algorithm is programmed to place beams in a grid unit.

The sequence of rebar placement consisting of beams and slabs was determined based on the preceding literature $[16,17]$. The two beam bars are usually placed first at both ends to fix stirrups, and then stirrups, bottom bars, top bars and capped stirrup-tie are placed, in that sequence. For this reason, the algorithm was programmed as such. Since the top beam bars are fixed under the 
capped stirruptie, the capped stirrup-tie should be installed first, by which the capped stirrup-ties are considered to be placed earlier than the top bars. However, the main top beam bars are actually placed inside, and then the capped stirrupties are fixed, so the algorithm was programmed as such. In terms of slab bars, lower bars of the middle strip in short direction that should be installed at the lowest bottom are placed first, and then bottom and top bars of the column strip in long direction, bent bars of the middle strip in long direction, lower rebars of the middle strip in long direction, bent bars of the middle strip in long direction, top bars of the column strip, top bars of the column strip in short direction, and top bars are placed, in that sequence. The algorithm was programmed as such.

In addition, if the top or bottom bars must be placed in two layers, erection bars or bar separators must be in position and tied across the top of the bottom bars to support the upper layer of rebars [18]. When taking the erection bars into account, the placement sequence can be different, but as the erection bars have an insignificant influence on the overall sequence of placement, they are not considered in this research.

Table 1. Placement sequences of beam and slab bars

\begin{tabular}{|c|c|c|}
\hline step & beam bars & slab bars \\
\hline 1 & top edge longitudinal bars & $\begin{array}{l}\text { (Dx)bottom bars, column and middle } \\
\text { strips }\end{array}$ \\
\hline 2 & stirrups & (Dy)bottom bars, column strips \\
\hline 3 & bottom longitudinal bars & (Dy)top bars, column strips \\
\hline 4 & second layer bottom bars & (Dx)bent bars, middle strips \\
\hline 5 & top longitudinal bars & (Dy)bottom bars, middle strips \\
\hline 6 & capped stirrup-ties & (Dy)bent bars, middle strips \\
\hline 7 & & (Dy)top bars, column strips \\
\hline 8 & & (Dx)top bars. column strips \\
\hline 9 & & $\begin{array}{l}\text { (both direction) short top bars, middle } \\
\text { strips }\end{array}$ \\
\hline
\end{tabular}

* Dx : short span direction, Dy : long span direction

\section{Case Example}

\subsection{Case Description}

The simulation of the placement obtained by the algorithm presented in the previous section was applied to a site to verify the validity of the system. The site was a 4-story middle-sized office that has the slab-beam-and-girder floor systems. Figure 2 indicates the lists of the beams and slabs used.

\begin{tabular}{|c|c|c|c|}
\hline \multicolumn{2}{|c|}{ TITLE } & \multicolumn{2}{|c|}{ List of Beam \& Girder } \\
\hline \multicolumn{4}{|c|}{$\mathrm{Fc}=21 \mathrm{Mpa} \quad \mathrm{Fy}=400 \mathrm{Mpa} \quad F y s=400 \mathrm{Mpa}$} \\
\hline \multicolumn{2}{|c|}{ Girder Number } & Both End & Center \\
\hline \multirow{3}{*}{ G1 } & & $8-H D 22$ & $5-H D 22$ \\
\hline & $\begin{array}{c}400 \\
X \\
800\end{array}$ & $\frac{\ldots . . .}{5-H D 22}$ & $\frac{\square}{8-\mathrm{HD} 22}$ \\
\hline & Stirrup & HD13-@ 150 & HD13-@250 \\
\hline \multirow{4}{*}{$\begin{array}{l}\text { G2 } \\
\text { G3 }\end{array}$} & & 4- HD19 & 4- HD19 \\
\hline & $\begin{array}{c}300 \\
x\end{array}$ & & 1 \\
\hline & & 4- HD19 & 4- HD19 \\
\hline & Stirrup & HD10-@150 & HD10-@250 \\
\hline \multirow{4}{*}{ B1 } & & 5- HD19 & 5- HD19 \\
\hline & $\begin{array}{c}400 \\
X \\
700\end{array}$ & & ][ \\
\hline & & 5- HD19 & 5- HD19 \\
\hline & Stirrup & HD10-@150 & HD10-@250 \\
\hline
\end{tabular}

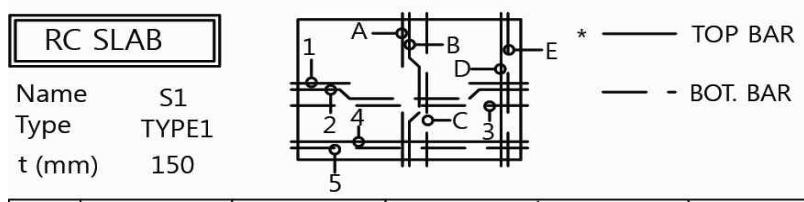

\begin{tabular}{|c|c|c|c|c|c}
\hline Lx & $A$ & $B$ & $C$ & $D$ & $E$ \\
\hline Ly & 1 & 2 & 3 & 4 & 5 \\
\hline \hline Lx & HD10@400 & HD13@400 & HD10@400 & HD10@400 & HD10@400 \\
\hline Ly & HD10@400 & HD13@400 & HD10@400 & HD10@400 & HD10@400 \\
\hline
\end{tabular}

Figure 2. Beam \& slab list in case example

As presented in the introduction, this research was restricted to the post-processes of the placing drawings, and rebar for each member was modeled 
using Revit Structure 2012. Figure 3 shows the models created using Revit Structure 2012.

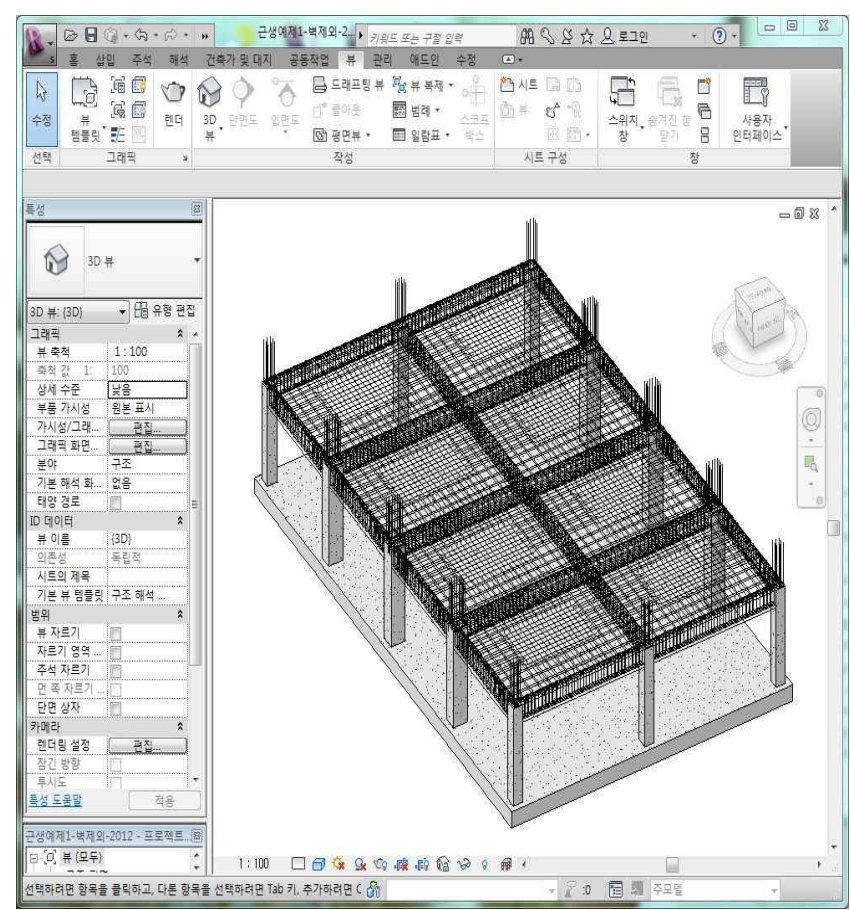

Figure 3. 3D model of case study using Autodesk Revit Structure 2012

Generally, bars are produced at standard lengths by bar producers. Therefore, when the span of a beam is long, bars should be connected by lap splice. However, a stress was put on the placement sequence here so that the span was displayed as a member, without taking the lap splices part into account.

\subsection{Clash detection}

Figure 4 is the screen showing the clash detection by the system. The rebars that were interfered with were shown in a list. The rebars turn red upon clicking the name on the list. Revit Structure 2012 assigned an ID to each rebar to enable its identification. When clashes are detected, the system was programmed to display the basic information of the rebar, including the ID and name. If necessary, the property information can be extracted and displayed upon a user' s request.

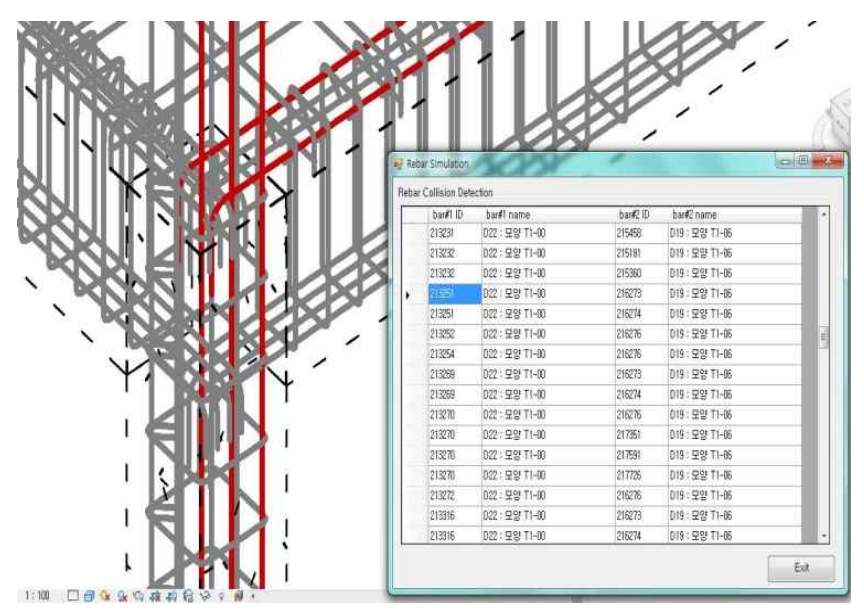

Figure 4. Rebar clash detection

To resolve the problem of clashes, the location of the rebar with the problem should be changed. In the case shown in Figure 4, the problem was resolved by moving the beam bars inside column bars. At this time, the net distance of the beam bars cannot be secured, and thus it should be reviewed.

\subsection{A stimulator for rebar placement}

Figure 5 illustrates the simulation of placing beam bars. From the left of the first raw top edge bars, stirrups and bottom bars in that order are presented, and from the left of the second raw, top bars, capped stirrup-ties and the third one of the beams are presented. With this system, users can simulate the placement sequence not only by detailed member unit but also by member group. Moreover, by controlling the window form in the right upper part on the screen, a user can simulate the sequence by stages. With the current stage displayed in the lower part of the screen, the user can move to a previous or next stage to check the sequence more thoroughly. In the middle of the window form displays the information of 

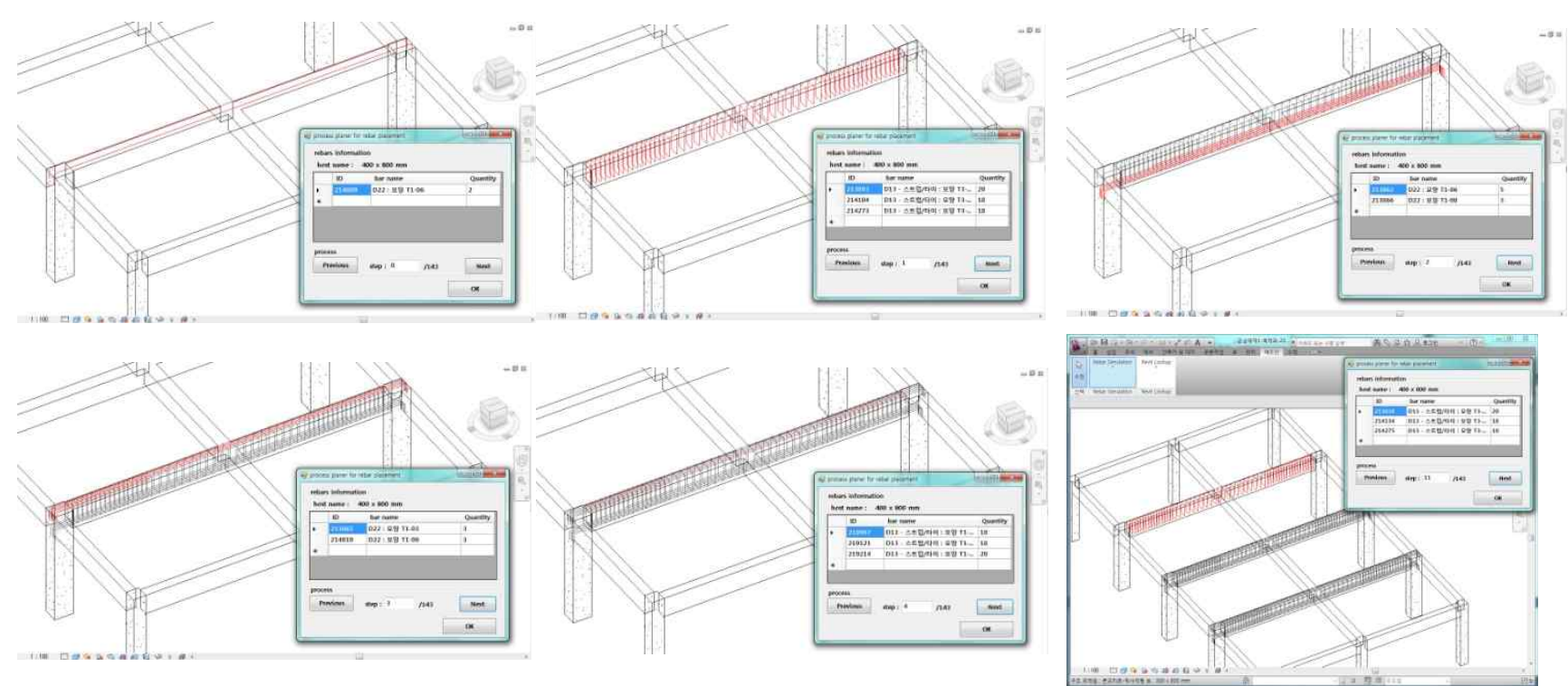

Figure 5. Placement sequence simulation of beam bars
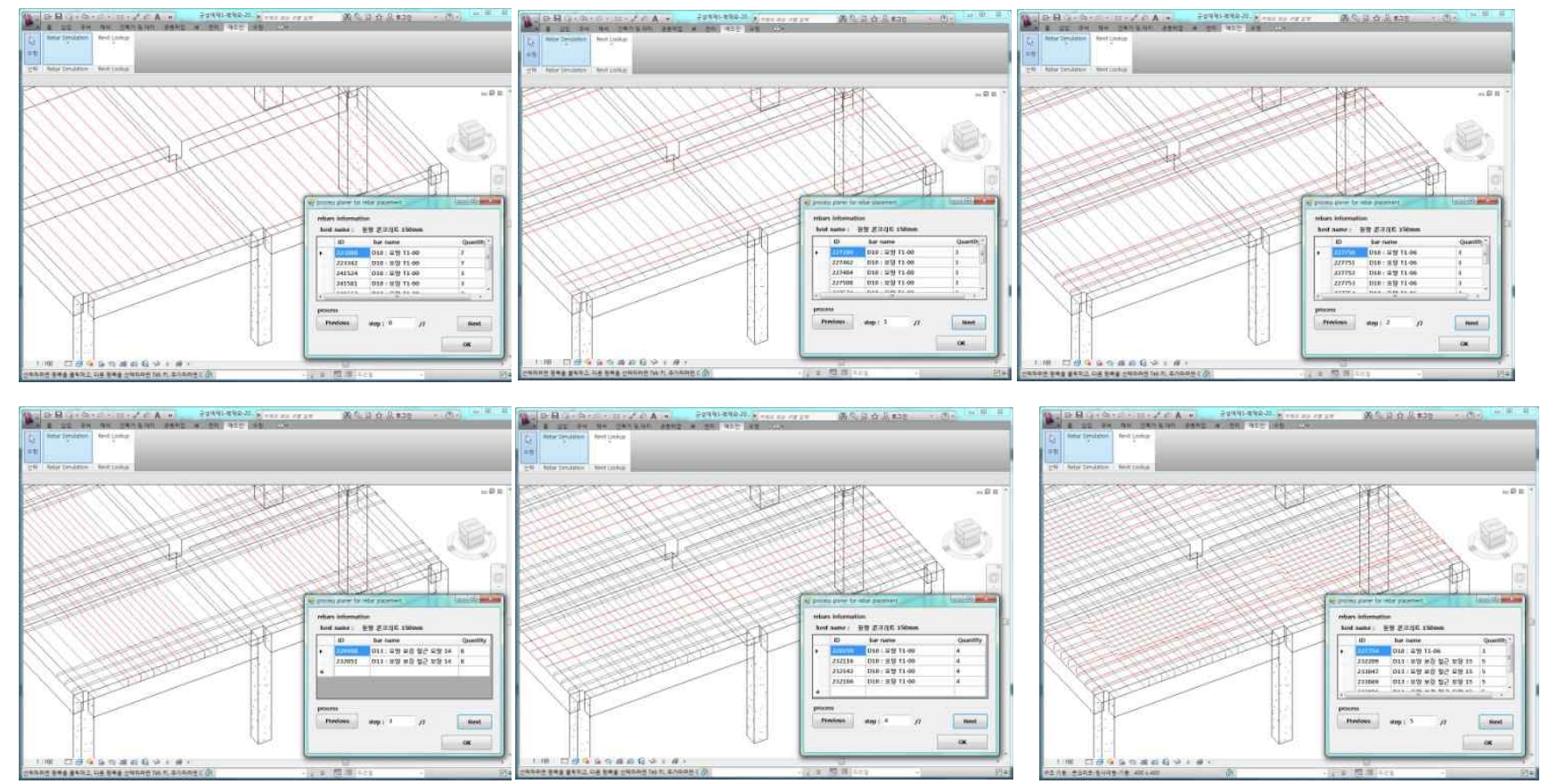

Figure 6. Placement sequence simulation of slab bars

rebars to be placed so that the user can check it conveniently.

Figure 6 illustrates the simulation of placing the slab bars. Here, the 6 steps of the placement sequence was shown, from the first bottom bars in the short direction and the sixth bent bars in the long direction.

\subsection{Expected effects of the system}

\subsubsection{Placing drawings check}

With this system, users can check whether any rebar is omitted after the placing drawings are prepared. Generally the placing drawings are prepared manually by a detailer, and it is likely to 
omit rebars in some cases. If the placing drawings are checked using a simulation, any omission of rebar can be identified visually so that the stability of the structure as well as the efficiency of managerial work is expected to be improved.

\subsubsection{Rebar model check}

The information of host members (base, column, wall, beam, slab, etc. concrete structure member to which rebars are placed) is stored when rebar is modeled using Revit Structure 2012. When a bar list is made up based on the rebar model data, the information is extracted by concrete host member group. Therefore, if any host member is assigned incorrectly, it can lead to error in the data by member group. However, this system allows users to check the detailed rebar placement by group member, which is believed that the error can be identified in advance.

\subsubsection{Bar fabricating in consideration of the placing sequence}

As described earlier, since bars are stacked randomly, the Ironworkers waste their time to find rebars they need, or they sometimes put wrong rebars together. The process should be improved for better productivity and quality control. Therefore, taking into account the placement sequence, it is needed to fabricate, unload and store the rebars. To do this, the placement sequence information by member group should be extracted and managed. This system is expected to raise efficiency of managerial work related in the rebar work since it can extract the information of rebar information by the placement sequence.

\subsubsection{Improvement of structural quality}

When using the clash detection, users can identify the structural problem(s) that might take place in the future. In addition, the structural quality is expected to be improved because the simulator for the rebar placement determines the placement sequence taking structural performance into account. That is, when a member with much rebar is placed first, the main bars that bear much load can be placed farthest from the neutral axis, and the structural stability can be enhanced.

\section{Limitations and future extensions}

This research focused on the simulation of the placement sequence, the modeling was performed by simplifying the rebar work, and the lap splices were ignored. However, the bar spacing should be checked in case of the lapped splice at the site. For this reason, the modeling needs to be conducted taking into account the elements such as the bar standard length and lap splice that can be found at an actual site.

In addition, BIM-based simulation performed did not consider the time spent in placing bars. The time spent in placing bars can vary depending on the number of Ironworkers or quality craftsmanship. When taking into account a condition similar to an actual site, the simulation is expected to be performed similarly compared to reality. Therefore, the actual time taken to place bars should be measured in the future to reflect it on the simulation program. The specific time spent in each section of the rebar work by the number of workers can be identified and utilized.

This research was performed in a relatively simple middle-sized office facility. Therefore, if this system is applied to a large-sized building structure, the problem(s) will be different from what was found in this research. The larger a building structure is, the larger the data is to be processed because more different types of rebars 
are used. If the case may be, the system slows down to handle the data. In addition, as a good many of rebars are placed in a structure, the entire structure of a building is difficult to identify on a monitor screen so that it should be magnified using a large-sized screen and a projector. If the structure is complex like this, the entire sequence can be identified on a screen larger than a general monitor screen, and there would be many requirements of the specification of the hardware. Therefore, the possible problems that might arise out of applying the problem to a complex structure should be considered.

\section{Conclusion}

A BIM-based simulator was developed to expand the usability of BIM and improve the quality and constructability of rebar work. The system can perform both clash detection and simulation of the placement sequence using Revit API of Autodesk. The geometric information of the center line extracted by Revit Structure 2012 was utilized, and when the distance between the center lines was smaller than the diameter of the rebar, a clash is considered to take place. The simulator was equipped with an algorithm that determines the placement sequence by member group to increase the structural stability and constructability of the beams and slabs. That is, the beams that should bear much load or have larger cross section were placed first, and the sequence was determined to reduce threading bars in and around previously placed bars.

From the actual application of this system to a site, the omission of rebar and error can be identified in advance, and thus the system can provide support to proceed with the rebar work as shown in the schedule, and the structural stability is expected to be secured. However, this research was carried out in a relatively small building structure, the system should be expanded to perform a simulation for a large construction project by taking the standard length and the lap splice into account as well as to incorporate the time spent based on the actual data on the time spent in placing bars at a real site.

\section{Acknowledgement}

This work was supported by a grant from 2011 Research Fund of Andong National University

\section{References}

1. Salim MD, Bernold LE. Design-Integrated Process Planner for Rebar Placement. Journal of Computing in Civil Engineering. 1995 April;9(2):157-67.

2. Park UY, Kim GH, Kang KI. A Study on the Actual Condition Analysis and Improvement or Rebar Work in Korean Building Construction. Journal of The Korea Institute of Building Construction. 2004 Sep;4(3):83-91.

3. Lee TO. A Study on the Actual Condition Survey of Apartment Rebar Work. Journal of The Korea Institute of Building Construction. 2008 April;8(2):71-79.

4. Cho HH, Park UY, Kang TK, Park HY, Yun, SH, Huh YK. Analysis of Re-bar Manufacturing System in Plant and its Facilitate Method. Korean Journal of Construction Engineering and Management. 2007 Sep;8(1):57-65.

5. Kim GH, Park WY, Kang YI. Develpment of a Improvement System for Quality \& Cost Management of Rebar Work in Korean Building Construction. Journal of the Architectural Institute of Korea Structure \& Construction Section. 2002 May;18(5):121-129.

6. Ham CS, Park JP, Park JK, Chung JY, Kim IH. A Study on the Development of Shop Drawings and Bar-bending Schedule Automation System for Apartment Housing. Journal of the Architectural Institute of Korea. 1999 August;15(8):111-19.

7. Park HY, Lee SH, Kang TK, Lee YS. Developing an Automatic System for Quantity Taking-off Cut and Bent Rebar and Making a Placing Drawing. Proceeding of Conference in Architectural Institute of Korea; 2007 Sep 26-27; Cheongju-Si, 
Korea. Seoul (Korea): Architectural Institute of Korea; 2007.

p. $358-63$.

8. Kim SK, Kim CK. Integrated Automation of Structural Design and Rebar Work in RC Structures. Journal of the Architectural Institute of Korea. 1994 Jan;10(1):113-22.

9. Lee KH, Park JH, Bang KS, Yun SH, Paek JH. A Study on Developing a BIM-based Construction Simulation Application. Journal of the Architectural Institute of Korea (Structure \& Construction Section). 2009 May;25(5):205-12.

10. Ahn HK, Seo HC, Kim JH, Kim JJ. The Problem of the Clash detection through BIM model and Improvement. Korea Institute of Construction and Management 2010 Conference; 2010 Oct 23-24; Cheongju-Si, Korea. Seoul (Korea); Korea Institute of Construction and Management; 2010. p. 401-2.

11. Cho HH, Kwan OS, Seo JW, Kim JY, Kang KI. Development of Interference Management System Based on 4D-CAD in Substructure Work. Journal of the Architectural Institute of Korea (Structure \& Construction Section). 2001 Sep;17(9):22532.

12. Lee JC. Definition and Implementation of Object Libraries for 4D Simulation. Journal of the Architectural Institute of Korea (Structure \& Construction Section). 2002 March;18 (3): $149-56$

13. Lee JC. Developing and Automated Module for Sche- duling and Quantity Estimation Based on 3D CAD Model Information towards Effective Use of 4D CAD Model Journal of the Architectural Institute of Korea (Structure \& Construction Section). 2004 Feb;20(2):15-22.

14. Kang LS. Improvement of Construction Scheduling and Process Control Functions in 4D CAD System. Journal of the Architectural Institute of Korea (Structure \& Construction Section). 2006 August;22(8):141-8.

15. Kang LS, Moon HS, Park SY. Application Meth- odology and Process Model of 4D CAD System through Project Life Cycle. Journal of the Architectural Institute of Korea (Structure \& Construction Section). 2008 July;24(7):127-34

16. Concrete Reinforcing Steel Institute(CRSI). Placing Reinforcing Bars 8th Ed. USA: CRSI; 2005. p. 12-20.

17. Park UY, Jeong HO, Kang YH, Kang TK, Cho HH. [The Theory and Practice of Rebar Placement]. Seoul (Korea): Daega; 2011. p. 122-55. Korean.

18. Jung HO, Cho HH, Park UY. A Study on the Improvement of Erection Bar Detailing in Domestic Building Construction. Journal of The Korea Institute of Building Construction. 2009 March;9(2):39-46. 